\title{
Oberlin transfer compared with nerve grafting for improving early supination in neonatal brachial plexus palsy
}

\author{
Kate W. C. Chang, MA, MS, ${ }^{1}$ Thomas J. Wilson, MD, ${ }^{2}$ Miriana Popadich, MSN, NP-C, ${ }^{1}$ \\ Susan H. Brown, PhD, ${ }^{3}$ Kevin C. Chung, MD, MS, ${ }^{4}$ and Lynda J. S. Yang, MD, PhD ${ }^{1}$ \\ Departments of ${ }^{1}$ Neurosurgery, ${ }^{3}$ Kinesiology, and ${ }^{4}$ Plastic Surgery, University of Michigan, Ann Arbor, Michigan; and ${ }^{2}$ Department \\ of Neurosurgery, Mayo Clinic, Rochester, Minnesota
}

\begin{abstract}
OBJECTIVE The use of nerve transfers versus nerve grafting for neonatal brachial plexus palsy (NBPP) remains controversial. In adult brachial plexus injury, transfer of an ulnar fascicle to the biceps branch of the musculocutaneous nerve (Oberlin transfer) is reportedly superior to nerve grafting for restoration of elbow flexion. In pediatric patients with NBPP, recovery of elbow flexion and forearm supination is an indicator of resolved NBPP. Currently, limited evidence exists of outcomes for flexion and supination when comparing nerve transfer and nerve grafting for NBPP. Therefore, the authors compared 1-year postoperative outcomes for infants with NBPP who underwent Oberlin transfer versus nerve grafting.
\end{abstract}

METHODS This retrospective cohort study reviewed patients with NBPP who underwent Oberlin transfer $(n=19)$ and nerve grafting $(n=31)$ at a single institution between 2005 and 2015. A single surgeon conducted intraoperative exploration of the brachial plexus and determined the surgical nerve reconstruction strategy undertaken. Active range of motion was evaluated preoperatively and postoperatively at 1 year.

RESULTS No significant difference between treatment groups was observed with respect to the mean change (pre- to postoperatively) in elbow flexion in adduction and abduction and biceps strength. The Oberlin transfer group gained significantly more supination $\left(100^{\circ}\right.$ vs $\left.19^{\circ} ; p<0.0001\right)$. Forearm pronation was maintained at $90^{\circ}$ in the Oberlin transfer group whereas it was slightly improved in the grafting group $\left(0^{\circ}\right.$ vs $\left.32^{\circ} ; p=0.02\right)$. Shoulder, wrist, and hand functions were comparable between treatment groups.

CONCLUSIONS The preliminary data from this study demonstrate that the Oberlin transfer confers an advantageous early recovery of forearm supination over grafting, with equivalent elbow flexion recovery. Further studies that monitor real-world arm usage will provide more insight into the most appropriate surgical strategy for NBPP.

https://thejns.org/doi/abs/10.3171/2017.8.PEDS17160

KEY WORDS neonatal brachial plexus palsy; Oberlin transfer; nerve grafting; peripheral nerve

E ACH year, neonatal brachial plexus palsy (NBPP) affects approximately 1.5 per 1000 live births in the United States. ${ }^{43,45}$ Stretching of the nerves comprising the brachial plexus during the perinatal period results in weakness or paralysis of the shoulder, elbow, wrist, and/ or hand. Approximately 10\%-40\% of infants with NBPP will have persistent NBPP at 1 year of age. ${ }^{11,43,56}$ Depending on the site and severity of the injury, timely diagnosis, early referral, and surgical intervention can potentially benefit infants with persistent NBPP to maximize recov- ery. Decision-making regarding management incorporates physical examination, electrodiagnostic testing (EDX), and imaging studies. ${ }^{6,10,49}$ Although indications for reconstruction timing and surgical approaches vary from center to center, the approach is largely determined by the site and severity of the injury. Infants with a flail arm, Horner's syndrome, or lack of recovery in hand or biceps functions at 3-6 months are considered by most to be candidates for surgical intervention. $3,4,20,23,42,55$

Nerve grafting has been the mainstay for nerve recon-

ABBREVIATIONS AROM = active range of motion; EDX = electrodiagnostic testing; ICF = International Classification of Functioning; MRC = Medical Research Council; $\mathrm{NBPP}=$ neonatal brachial plexus palsy.

SUBMITTED March 29, 2017. ACCEPTED August 1, 2017.

INCLUDE WHEN CITING Published online December 8, 2017; DOI: 10.3171/2017.8.PEDS17160. 
struction in restoring elbow/biceps function in the NBPP population, with the Oberlin transfer more recently becoming a viable, safe alternative. Due to the complexity of the injury, the consensus regarding nerve grafting versus Oberlin transfer has not been established. Early case series of patients with NBPP undergoing Oberlin transfer have suggested favorable outcomes in cases with upper brachial plexus lesions (Erb's palsy) and delayed referral., $2,16,46$ However, partial or inconsistent recovery of elbow flexion and concern for donor site morbidity have limited the use of the Oberlin transfer in infants with NBPP. 33,39

Recent publications have established the safety of the Oberlin transfer and presented results comparable to those for nerve grafting to improve elbow flexion function. However, disparities in the outcome measures used to evaluate NBPP postoperatively have made it challenging for readers to draw conclusions. ${ }^{15,18,26,29,48}$ Furthermore, data on quality of movement and real-world arm use are limited in the literature. Most treatment algorithms target restoration of elbow flexion; however, recovery of forearm supination could also influence the quality of movement. Currently, there is no study that compares the Oberlin transfer with nerve grafting as a primary nerve reconstruction strategy in infants with NBPP. The goal of this study was to compare 1-year postoperative outcomes in elbow flexion, forearm supination, and forearm pronation in infants with NBPP who underwent Oberlin transfer versus nerve grafting.

\section{Methods \\ Study Design}

This retrospective cohort study reviewed infants with NBPP who underwent Oberlin transfer $(n=19)$ and nerve grafting $(\mathrm{n}=31)$ for restoration of elbow flexion/forearm supination at a single institution between 2005 and 2015 . Data were retrieved from an institutional review boardapproved institutional data repository. We collected patient demographic data and NBPP-related factors at the initial clinic visit. An interdisciplinary brachial plexus team including neurosurgeons, physiatrists, and occupational therapists evaluated and diagnosed infants with NBPP via physical examination, EDX, and/or imaging evaluation. None of the patients had previous surgical intervention prior to initial assessment.

\section{Outcomes of Interest}

A certified occupational therapist assessed active range of motion (AROM) as well as biceps power using the Medical Research Council (MRC) grading scale preoperatively and 1 year postoperatively. The physical evaluation was standardized regardless of the surgical procedures. Primary outcomes of the current study included AROM of elbow flexion in adduction, elbow flexion in abduction, forearm supination, and forearm pronation, because these joints were relevant to the targeted movement after Oberlin transfer; secondary supportive outcomes reflecting the potential effects of contiguous joints included AROM of shoulder forward flexion, external rotation, internal rotation, abduction, extension, wrist extension, and finger flexion.
Patient demographic data included age at operation, sex, race, NBPP-involved side (left vs right), Narakas grade (numbers of nerve roots injured), and injury type (preganglionic, postganglionic, or mixed). The Narakas grade was not applied uniformly at 2-3 weeks of age as originally described by Narakas and subsequently suggested by Birch. ${ }^{7,37}$ Rather, the Narakas grade was determined by a single surgeon via either: 1) physical examination and neurological assessment at approximately 1 week of age or at initial clinical appointment, or 2) mother's or obstetrician's report of child's arm/hand movements at birth. The Narakas grade was dichotomized into Grade I/II versus III/IV in the current study. Injury type was determined by intraoperative assessment of the nerve roots in all cases. Patient demographic data; biceps MRC grade; and AROM of elbow flexion in adduction, elbow flexion in abduction, forearm supination, forearm pronation, shoulder forward flexion, external rotation, internal rotation, abduction, extension, wrist extension, and finger flexion were compared between the group undergoing Oberlin transfer and the group undergoing nerve grafting.

\section{Surgical Decision-Making}

Preoperative imaging and EDX were used as an extension of clinical examination and as a supportive indication for surgery. However, the surgical decision-making regarding nerve reconstruction strategy was primarily based on findings during intraoperative exploration of the brachial plexus. If the C-5 and C-6 nerve roots were available for grafting, then nerve grafting was performed for reconstruction; if only a single nerve root (C-5 or C-6) was available, it was directed to the anterior division of the upper trunk via grafting. Oberlin transfer was performed in cases of upper root avulsions or late presentation; a single surgeon performed all nerve transfers using the standard techniques of microsuture and tissue glue. EDX, rationale for surgery, and additional transfer procedures are included in the Appendix.

\section{Statistical Analysis}

We applied descriptive statistics for patient demographic data and NBPP-related factors. AROM for each movement at the initial preoperative visit, 1-year postoperative visit, and the mean AROM changes from the preoperative to the postoperative visit were summarized. Student's t-test for continuous variables, the Mann-Whitney U-test for ordinal variables, and the chi-square test or Fisher's exact test for categorical variables were applied to investigate differences between the Oberlin transfer and nerve grafting groups. A p $<0.05$ was considered statistically significant. Commercially available software was used for all analyses (IBM SPSS version 22; IBM Corp.).

\section{Results \\ Patient Demographic Data}

The Oberlin transfer and nerve grafting groups were similar with respect to patient demographic data, with the exception of lesion type (Table 1). On average, both groups were seen before 3 months of age; there was a trend toward the nerve grafting group undergoing operation ear- 
TABLE 1. Patient demographic data

\begin{tabular}{|c|c|c|c|}
\hline \multirow[b]{2}{*}{ Variable } & \multicolumn{2}{|c|}{ Surgery Group (\%) } & \multirow{2}{*}{$\begin{array}{c}p \\
\text { Value }\end{array}$} \\
\hline & Oberlin Transfer & Graft & \\
\hline No. of patients & 19 & 31 & \\
\hline \multicolumn{4}{|l|}{ Mean age $\pm S D$, mos } \\
\hline At initial appointment & $2.8 \pm 2.5$ & $2.5 \pm 2.3$ & 0.60 \\
\hline At op & $7.1 \pm 1.8$ & $6.0 \pm 1.9$ & 0.06 \\
\hline Sex & & & 0.64 \\
\hline Male & $8(42)$ & $11(35)$ & \\
\hline Female & $11(58)$ & $20(65)$ & \\
\hline Race & & & 0.78 \\
\hline White & $13(68)$ & $20(65)$ & \\
\hline Other & $6(32)$ & $11(35)$ & \\
\hline NBPP-involved side & & & 0.67 \\
\hline $\mathrm{Lt}$ & $11(58)$ & $16(52)$ & \\
\hline $\mathrm{Rt}$ & $8(42)$ & $15(48)$ & \\
\hline Narakas grade & & & 0.11 \\
\hline I/II & $13(68)$ & $14(45)$ & \\
\hline III/IV & $6(32)$ & $17(55)$ & \\
\hline Lesion type & & & $<0.001$ \\
\hline Preganglionic only & $13(68)$ & $0(0)$ & \\
\hline Postganglionic only & $6(32)$ & $20(65)$ & \\
\hline Mixed* & $0(0)$ & $11(35)$ & \\
\hline
\end{tabular}

lier (6 months) compared with the Oberlin transfer group (7 months), but this did not reach statistical significance $(p=0.06)$. The majority of patients in both groups were white (68\% in Oberlin transfer; $65 \%$ in nerve graft repair) and female $(58 \%$ in Oberlin transfer; $65 \%$ in nerve graft repair). Fifty-five percent were Narakas Grade III/IV in the nerve grafting group and $32 \%$ in the Oberlin transfer group, with no statistical significance. The only difference between the groups was observed for lesion type; all lesions were postganglionic for C-5 in the nerve grafting group, whereas only $32 \%$ were postganglionic in the Oberlin transfer group.

\section{Comparison of Outcomes}

Preoperative AROM of elbow flexion in adduction and abduction, biceps MRC grade, and forearm pronation were significantly better in the group of patients who underwent Oberlin transfer (Table 2). At 1 year postoperatively, the difference in AROM of elbow flexion in adduction and abduction and biceps MRC grade persisted, with the Oberlin transfer group exceeding the AROM of the nerve grafting group. The difference in forearm pronation was lost, while the Oberlin transfer group significantly exceeded the nerve grafting group in forearm supination.

The mean AROM changes from the preoperative visit to the 1-year postoperative visit were compared (Table 2). Similar gains were observed for elbow flexion in abduction and adduction for both treatment groups, with no statistical significance. However, the Oberlin transfer group showed a larger gain in supination compared with the nerve grafting group $\left(100^{\circ}\right.$ vs $19^{\circ}$; $\left.\mathrm{p}<0.0001\right)$. Full forearm pronation was maintained in the Oberlin transfer group, while the nerve grafting group improved $32^{\circ}$ postoperatively $\left(0^{\circ}\right.$ vs $\left.32^{\circ} ; \mathrm{p}=0.02\right)$.

Regarding the secondary outcomes of arm continuity, our results showed that the Oberlin transfer group had advantageous shoulder, wrist, and finger AROM outcomes compared with the nerve grafting group at 1 year postoperatively, although the AROM changes from preoperative to postoperative visits were equivalent between the groups (Table 3).

\section{Discussion}

Surgical treatment for infants with NBPP has evolved over the last decade; however, the results for Oberlin transfer and nerve grafting are still under debate. To our knowledge, the current study presents the first series comparing Oberlin transfer and nerve grafting as primary nerve reconstruction strategies for infants with NBPP. At the 1-year follow-up, both techniques restored similar mean AROM in elbow flexion, whereas Oberlin transfer achieved advantageous forearm supination compared with nerve grafting. ${ }^{31}$

Although surgical decision-making varies from center to center, surgical intervention is typically indicated if biceps function has not recovered sufficiently to allow the infant to get hand to mouth by 6 months of age. ${ }^{20,23,55}$ Our specific decision algorithm has been published. ${ }^{49}$ Nerve transfer and nerve grafting are the primary surgical techniques for treating infants with NBPP. The specific treat-

TABLE 2. Elbow and forearm AROM at 1-year follow-up

\begin{tabular}{|c|c|c|c|c|c|c|c|c|c|}
\hline \multirow[b]{2}{*}{ Measure } & \multicolumn{2}{|c|}{ Preop AROM $\left(^{\circ}\right)$} & \multirow[b]{2}{*}{$\begin{array}{c}p \\
\text { Value }\end{array}$} & \multicolumn{2}{|c|}{$\begin{array}{l}\text { 1-Yr Postop } \\
\text { AROM }\left(^{\circ}\right)\end{array}$} & \multirow[b]{2}{*}{$\begin{array}{c}p \\
\text { Value }\end{array}$} & \multicolumn{2}{|c|}{$\begin{array}{c}\text { Preop vs Postop AROM } \\
\text { Improvement }\left({ }^{\circ}\right)\end{array}$} & \multirow[b]{2}{*}{$\begin{array}{c}\mathrm{p} \\
\text { Value }\end{array}$} \\
\hline & $\begin{array}{l}\text { Oberlin } \\
(n=19)\end{array}$ & $\begin{array}{c}\text { Graft } \\
(n=31)\end{array}$ & & $\begin{array}{l}\text { Oberlin } \\
(n=12)\end{array}$ & $\begin{array}{c}\text { Graft } \\
(n=28)\end{array}$ & & $\begin{array}{l}\text { Oberlin } \\
(n=12)\end{array}$ & $\begin{array}{c}\text { Graft } \\
(n=28)\end{array}$ & \\
\hline Elbow flexion in adduction & $28 \pm 35$ & $5 \pm 39$ & 0.04 & $82 \pm 37$ & $47 \pm 40$ & 0.01 & $54 \pm 40$ & $37 \pm 47$ & 0.27 \\
\hline Elbow flexion in abduction & $51 \pm 45$ & $3 \pm 40$ & $<0.0001$ & $108 \pm 39$ & $61 \pm 44$ & 0.004 & $58 \pm 40$ & $62 \pm 43$ & 0.74 \\
\hline Median MRC strength of biceps (range) & $2(0-3)$ & $0(0-2)$ & 0.022 & $3(0-4)$ & $2(0-4)$ & 0.025 & $1(0-4)$ & $1(0-4)$ & 0.77 \\
\hline Forearm supination & $-67 \pm 38$ & $-61 \pm 42$ & 0.60 & $31 \pm 39$ & $-39 \pm 55$ & $<0.0001$ & $100 \pm 54$ & $19 \pm 56$ & $<0.0001$ \\
\hline Forearm pronation & $90 \pm 0$ & $52 \pm 69$ & 0.005 & $90 \pm 0$ & $87 \pm 17$ & 0.52 & $0 \pm 0$ & $32 \pm 66$ & 0.02 \\
\hline
\end{tabular}

Values expressed as the mean \pm SD unless otherwise indicated. 
TABLE 3. Shoulder and hand AROM at 1-year follow-up

\begin{tabular}{|c|c|c|c|c|c|c|c|c|c|}
\hline \multirow[b]{2}{*}{ Measure } & \multicolumn{2}{|c|}{ Preop AROM $\left(^{\circ}\right)$} & \multirow[b]{2}{*}{$\begin{array}{c}p \\
\text { Value }\end{array}$} & \multicolumn{2}{|c|}{ 1-Yr Postop AROM $\left(^{\circ}\right)$} & \multirow[b]{2}{*}{$\begin{array}{c}p \\
\text { Value }\end{array}$} & \multicolumn{2}{|c|}{$\begin{array}{l}\text { Preop vs Postop AROM } \\
\text { Improvement }\left(\left(^{\circ}\right)\right.\end{array}$} & \multirow[b]{2}{*}{$\begin{array}{c}p \\
\text { Value }\end{array}$} \\
\hline & $\begin{array}{l}\text { Oberlin } \\
(n=19)\end{array}$ & $\begin{array}{c}\text { Graft } \\
(n=31)\end{array}$ & & $\begin{array}{l}\text { Oberlin } \\
(n=12)\end{array}$ & $\begin{array}{c}\text { Graft } \\
(n=28)\end{array}$ & & $\begin{array}{l}\text { Oberlin } \\
(n=12)\end{array}$ & $\begin{array}{c}\text { Graft } \\
(n=28)\end{array}$ & \\
\hline Shoulder flexion & $55 \pm 41$ & $28 \pm 29$ & 0.01 & $105 \pm 41$ & $75 \pm 37$ & 0.03 & $46 \pm 33$ & $48 \pm 49$ & 0.90 \\
\hline Shoulder abduction & $41 \pm 36$ & $21 \pm 30$ & 0.03 & $91 \pm 35$ & $58 \pm 40$ & 0.02 & $50 \pm 24$ & $39 \pm 51$ & 0.37 \\
\hline Shoulder extension & $3 \pm 12$ & $-2 \pm 10$ & 0.12 & $10 \pm 14$ & $1 \pm 4$ & 0.07 & $5 \pm 23$ & $3 \pm 11$ & 0.81 \\
\hline Shoulder exorotation adduction & $-64 \pm 49$ & $-67 \pm 46$ & 0.84 & $-6 \pm 53$ & $-37 \pm 49$ & 0.09 & $55 \pm 71$ & $31 \pm 60$ & 0.27 \\
\hline Shoulder exorotation abduction & $-46 \pm 45$ & $-69 \pm 45$ & 0.08 & $10 \pm 53$ & $-30 \pm 55$ & 0.04 & $60 \pm 55$ & $40 \pm 65$ & 0.36 \\
\hline Shoulder endorotation adduction & $70 \pm 0$ & $43 \pm 53$ & 0.007 & $70 \pm 0$ & $65 \pm 18$ & 0.36 & $0 \pm 0$ & $23 \pm 46$ & 0.02 \\
\hline Shoulder endorotation abduction & $70 \pm 0$ & $39 \pm 54$ & 0.004 & $70 \pm 0$ & $55 \pm 35$ & 0.03 & $0 \pm 0$ & $22 \pm 58$ & 0.07 \\
\hline Wrist extension & $21 \pm 52$ & $-19 \pm 57$ & 0.02 & $55 \pm 23$ & $8 \pm 50$ & 0.003 & $30 \pm 58$ & $26 \pm 61$ & 0.84 \\
\hline Finger flexion & $90 \pm 0$ & $61 \pm 51$ & 0.003 & $90 \pm 0$ & $52 \pm 52$ & 0.001 & $0 \pm 0$ & $-14 \pm 65$ & 0.26 \\
\hline
\end{tabular}

Values expressed as the mean $\pm S D$.

ment strategy implemented for a given patient depends on a variety of factors, including age, lesion type, lesion site, and timing of presentation. Nerve grafting has been performed in the NBPP population for more than 3 decades; it is recommended for patients who present with rupture (postganglionic) of the upper nerve roots of the brachial plexus (C-5 and C-6), ${ }^{9,19,36}$

Oberlin nerve transfer was introduced in the early 1990s and has since been widely used in traumatic pediatric BPP and adult brachial plexus injury, particularly for avulsion (preganglionic) lesions where viable proximal nerve stumps are not available. ${ }^{13,35,40}$ The consensus is that nerve transfer is an indicated option in cases of late presentation, failed primary nerve reconstruction, isolated deficit, absence of proximal root for grafting, and multiple nerve root avulsions (preganglionic lesion). 2,14,25,29,51 Although these specific indications are not highly controversial, what remains debated is whether use of the Oberlin transfer should be expanded in the NBPP population. ${ }^{14,15,25,34,51}$

Inconsistent outcome reporting in the current literature makes this discussion challenging because of the difficulty in comparing outcomes for nerve transfer and nerve grafting. ${ }^{8,17,18,22,24,26,30,39,41,54}$ Potential advantages of nerve transfer include safer technique, shorter operative time, and less regeneration time needed for recovery compared with nerve grafting. ${ }^{26}$ Currently, the International Federation of Societies for Surgery of the Hand Committee has recognized similar results for nerve grafting and nerve transfer in patients with NBPP with Erb's palsy but continue to recommend brachial plexus exploration and nerve grafting when feasible..$^{51}$ Physicians should use the information from electrodiagnostic/imaging studies and physical examination to develop a preoperative surgical plan to optimize outcome. ${ }^{19,21,25,49,50,52,56}$

Our results demonstrate that early forearm supination is significantly improved with Oberlin transfer compared with nerve grafting, whereas elbow flexion recovery was the same in both groups. Despite the biceps muscle being a key supinator of the forearm, previous studies have not compared forearm supination function in infants with
NBPP treated with nerve transfer versus nerve grafting. ${ }^{26,29}$ Recovery of forearm supination increases the ability for children to bring their hand to mouth, making it an important consideration. Recovery of supination could potentially improve the quality of movement during daily activities such as feedings, grooming, and lifting. ${ }^{32}$

However, the inconsistency of outcome measures for NBPP recovery make it challenging to evaluate the quality of movement. In a 2013 systematic review, the authors elucidated disparities in NBPP outcome evaluation in the current literature, which posed difficulties when evaluating the overall impact and effectiveness of clinical treatments in a comparative fashion across the various specialties. ${ }^{12}$ Furthermore, the majority of the outcome measures focus on the International Classification of Functioning (ICF) Body Function and Structures domain, with limited outcome measures regarding ICF Activity and Participation domains. ${ }^{27}$ It is critical to incorporate physical function into patients' participation in daily activities and psychosocial status. All ICF domains should be considered when evaluating patients with NBPP in a comprehensive manner. Further studies that remotely monitor real-world arm movement using body-worn movement capture technology will provide more insight into spontaneous use of the affected arm in activities of daily living.

To our knowledge, this is the first study to compare the effect of Oberlin transfer versus nerve grafting on biceps reinnervation among an NBPP population at a single institution. Anatomically, biceps muscle function could also be affected by surrounding shoulder or hand movements. ${ }^{5,26,38,44,47,53}$ For infants with NBPP, impaired growth of denervated biceps muscle may lead to weakness or even contracture of the affected area. The process of muscle remodeling might reorganize the muscle structure such that infants with NBPP tend to compensate for the lack of biceps function with shoulder subscapularis or wrist muscles. For example, children could achieve elbow flexion by pronating the forearm with wrist flex while swinging the arm against gravity (Steindler effect). ${ }^{1}$

However, our results show that shoulder, wrist, and finger improvements are comparable between the treatment 
groups, which is consistent with published results. ${ }^{26,28,41}$ This finding eliminates shoulder or hand movement compensation as the confounder for the biceps recovery. Hence, given similar recovery of shoulder and hand AROM in both treatment groups, it is evident that the improvement of forearm supination indicates a true biceps recovery following Oberlin transfer.

Limitations exist in the current study. Due to institutional differences, surgeons' experience, small sample size, and the retrospective design of the study, the sample might not be sufficient to detect differences between treatment groups, and the results might not be generalizable to the entire NBPP population. Furthermore, lesion type and lesion site vary between the treatment groups. It is possible that an extensive lesion site may affect the postoperative outcome, especially in the Oberlin transfer group, because an extensive lesion might affect the availability of functional fascicles in the ulnar nerve. However, all of the patients who underwent Oberlin transfer had recovered hand function prior to surgery, which indicated sufficient functional fascicles in the ulnar nerve to conduct the Oberlin transfer.

In addition, it is possible that the recovery outcomes could be the result of natural recovery. During nerve grafting, C-5 and/or C-6 are cut and then grafts are inserted such that all pathways out of C-5 and C- 6 are lost at the time of surgery. During the Oberlin procedure, only the biceps branch is cut and the rest of the pathways out of C-5 and C-6 are intact; recovery of elbow flexion could occur as part of spontaneous recovery through the brachialis or brachioradialis muscles, which are not disrupted by the Oberlin procedure. Future studies comparing natural recovery versus surgical outcomes in NBPP might shed light on this topic.

Finally, to reinnervate the targeted muscle, the proximal nerve stump must regenerate through the distal stump following both procedures. ${ }^{57}$ The regenerating process could take up to 3 years before functional recovery occurs; therefore, future studies with a larger sample size and at least a 3 -year postoperative follow-up could provide more evidence on this topic.

\section{Conclusions}

We have demonstrated that Oberlin transfer confers advantageous early recovery of forearm supination compared with nerve grafting in infants with NBPP. Regained elbow flexion is equivalent in both procedures. Combined elbow flexion and forearm supination recoveries might improve quality of movement in infants with NBPP. However, current outcome measures mainly focus on ICF Body Function and Structure, whereas information regarding quality of movement is lacking. Future studies that monitor real-world arm usage will provide more insight into spontaneous use of the affected arm in activities of daily living and shed light on the appropriate surgical strategy for infants with NBPP.

\section{Acknowledgments}

We acknowledge Connie McGovern, Denise Justice, and Lynnette Rasmussen for their contributions toward data collection and data management.

\section{References}

1. Al-Qattan MM: Elbow flexion reconstruction by Steindler flexorplasty in obstetric brachial plexus palsy. J Hand Surg [Br] 30:424-427, 2005

2. Al-Qattan MM: Oberlin's ulnar nerve transfer to the biceps nerve in Erb's birth palsy. Plast Reconstr Surg 109:405407, 2002

3. Al-Qattan MM, Clarke HM, Curtis CG: The prognostic value of concurrent Horner's syndrome in total obstetric brachial plexus injury. J Hand Surg [Br] 25:166-167, 2000

4. Bade SA, Lin JC, Curtis CG, Clarke HM: Extending the indications for primary nerve surgery in obstetrical brachial plexus palsy. BioMed Res Int 2014:627067, 2014

5. Bahm J: The surgical strategy to correct the rotational imbalance of the glenohumeral joint after brachial plexus birth injury. J Brachial Plex Peripher Nerve Inj 11:e10e17, 2016

6. Bertelli JA, Ghizoni MF: The towel test: a useful technique for the clinical and electromyographic evaluation of obstetric brachial plexus palsy. J Hand Surg [Br] 29:155-158, 2004

7. Birch R: Obstetric brachial plexus palsy. J Hand Surg [Br] 27:3-8, 2002

8. Blaauw G, Slooff AC: Transfer of pectoral nerves to the musculocutaneous nerve in obstetric upper brachial plexus palsy. Neurosurgery 53:338-342, 2003

9. Boome RS, Kaye JC: Obstetric traction injuries of the brachial plexus. Natural history, indications for surgical repair and results. J Bone Joint Surg Br 70:571-576, 1988

10. Borschel GH, Clarke HM: Obstetrical brachial plexus palsy. Plast Reconstr Surg 124 (1 Suppl):144e-155e, 2009

11. Chang KW, Ankumah NA, Wilson TJ, Yang LJ, Chauhan SP: Persistence of neonatal brachial plexus palsy associated with maternally reported route of delivery: review of 387 cases. Am J Perinatol 33:765-769, 2016

12. Chang KW, Justice D, Chung KC, Yang LJ: A systematic review of evaluation methods for neonatal brachial plexus palsy: a review. J Neurosurg Pediatr 12:395-405, 2013

13. Chim H, Kircher MF, Spinner RJ, Bishop AT, Shin AY: Reconstruction of pediatric brachial plexus injuries with nerve grafts and nerve transfers. J Hand Surg Am 39:17711778,2014

14. Davidge KM, Yee A, Moore AM, Mackinnon SE: The supercharge end-to-side anterior interosseous-to-ulnar motor nerve transfer for restoring intrinsic function: clinical experience. Plast Reconstr Surg 136:344e-352e, 2015

15. de Matos Figueiredo R, Grechi G, de Amoreira Gepp R: Oberlin's procedure in children with obstetric brachial plexus palsy. Childs Nerv Syst 32:1085-1091, 2016

16. Dragu A, Horch RE, Wirth S, Ingianni G: Bilateral obstetric brachial plexus paralysis: a case report. Klin Padiatr 221:57-59, 2009

17. El-Gammal TA, Abdel-Latif MM, Kotb MM, El-Sayed A, Ragheb YF, Saleh WR, et al: Intercostal nerve transfer in infants with obstetric brachial plexus palsy. Microsurgery 28:499-504, 2008

18. Ghanghurde BA, Mehta R, Ladkat KM, Raut BB, Thatte MR: Distal transfers as a primary treatment in obstetric brachial plexus palsy: a series of 20 cases. J Hand Surg Eur Vol 41:875-881, 2016

19. Gilbert A, Brockman R, Carlioz H: Surgical treatment of brachial plexus birth palsy. Clin Orthop Relat Res (264):39-47, 1991

20. Gilbert A, Tassin JL: [Surgical repair of the brachial plexus in obstetric paralysis.] Chirurgie 110:70-75, 1984 (Fr)

21. Haerle M, Gilbert A: Management of complete obstetric brachial plexus lesions. J Pediatr Orthop 24:194-200, 2004

22. Kawabata H, Kawai H, Masatomi T, Yasui N: Accessory nerve neurotization in infants with brachial plexus birth palsy. Microsurgery 15:768-772, 1994 
23. Kawabata H, Masada K, Tsuyuguchi Y, Kawai H, Ono K, Tada R: Early microsurgical reconstruction in birth palsy. Clin Orthop Relat Res (215):233-242, 1987

24. Kawabata H, Shibata T, Matsui Y, Yasui N: Use of intercostal nerves for neurotization of the musculocutaneous nerve in infants with birth-related brachial plexus palsy. J Neurosurg 94:386-391, 2001

25. Kozin SH: Nerve transfers in brachial plexus birth palsies: indications, techniques, and outcomes. Hand Clin 24:363376, v, 2008

26. Ladak A, Morhart M, O'Grady K, Wong JN, Chan KM, Watt MJ, et al: Distal nerve transfers are effective in treating patients with upper trunk obstetrical brachial plexus injuries: an early experience. Plast Reconstr Surg 132:985e-992e, 2013

27. Lemmens RJ, Timmermans AA, Janssen-Potten YJ, Smeets RJ, Seelen HA: Valid and reliable instruments for arm-hand assessment at ICF activity level in persons with hemiplegia: a systematic review. BMC Neurol 12:21, 2012

28. Lin JC, Schwentker-Colizza A, Curtis CG, Clarke HM: Final results of grafting versus neurolysis in obstetrical brachial plexus palsy. Plast Reconstr Surg 123:939-948, 2009

29. Little KJ, Zlotolow DA, Soldado F, Cornwall R, Kozin SH: Early functional recovery of elbow flexion and supination following median and/or ulnar nerve fascicle transfer in upper neonatal brachial plexus palsy. J Bone Joint Surg Am 96:215-221, 2014

30. Luo PB, Chen L, Zhou CH, Hu SN, Gu YD: Results of intercostal nerve transfer to the musculocutaneous nerve in brachial plexus birth palsy. J Pediatr Orthop 31:884-888, 2011

31. Mackinnon SE, Novak CB, Myckatyn TM, Tung TH: Results of reinnervation of the biceps and brachialis muscles with a double fascicular transfer for elbow flexion. J Hand Surg Am 30:978-985, 2005

32. Magermans DJ, Chadwick EK, Veeger HE, van der Helm FC: Requirements for upper extremity motions during activities of daily living. Clin Biomech (Bristol, Avon) 20:591-599, 2005

33. Malessy MJA, Pondaag W: Estratégias cirúgicas e técnicas de reparo das lesões do plexo braquial ao nascimento, in Siqueira MG, Martins RS (eds): Lesões do plexo braquial. Rio de Janeiro: DiLivros Editora, 2011, pp 333-343

34. McRae MC, Borschel GH: Transfer of triceps motor branches of the radial nerve to the axillary nerve with or without other nerve transfers provides antigravity shoulder abduction in pediatric brachial plexus injury. Hand (NY) 7:186-190, 2012

35. Merrell GA, Barrie KA, Katz DL, Wolfe SW: Results of nerve transfer techniques for restoration of shoulder and elbow function in the context of a meta-analysis of the English literature. J Hand Surg Am 26:303-314, 2001

36. Meyer RD: Treatment of adult and obstetrical brachial plexus injuries. Orthopedics 9:899-903, 1986

37. Narakas AO: Obstetrical brachial plexus injuries, in Lamb DW (ed): The Paralysed Hand. New York: Churchill Livingstone, 1987, pp 116-135

38. Nikolaou S, Peterson E, Kim A, Wylie C, Cornwall R: Impaired growth of denervated muscle contributes to contracture formation following neonatal brachial plexus injury. $\mathbf{J}$ Bone Joint Surg Am 93:461-470, 2011

39. Noaman HH, Shiha AE, Bahm J: Oberlin's ulnar nerve transfer to the biceps motor nerve in obstetric brachial plexus palsy: indications, and good and bad results. Microsurgery 24:182-187, 2004

40. Oberlin C, Béal D, Leechavengvongs S, Salon A, Dauge MC, Sarcy JJ: Nerve transfer to biceps muscle using a part of ulnar nerve for C5-C6 avulsion of the brachial plexus: anatomical study and report of four cases. J Hand Surg Am 19:232-237, 1994

41. Pondaag W, de Boer R, van Wijlen-Hempel MS, HofstedeBuitenhuis SM, Malessy MJ: External rotation as a result of suprascapular nerve neurotization in obstetric brachial plexus lesions. Neurosurgery 57:530-537, 2005

42. Pondaag W, Malessy MJ: Recovery of hand function following nerve grafting and transfer in obstetric brachial plexus lesions. J Neurosurg 105 (1 Suppl):33-40, 2006

43. Pondaag W, Malessy MJ, van Dijk JG, Thomeer RT: Natural history of obstetric brachial plexus palsy: a systematic review. Dev Med Child Neurol 46:138-144, 2004

44. Savva N, McAllen CJ, Giddins GE: The relationship between the strength of supination of the forearm and rotation of the shoulder. J Bone Joint Surg Br 85:406-407, 2003

45. Sheffler LC, Lattanza L, Hagar Y, Bagley A, James MA: The prevalence, rate of progression, and treatment of elbow flexion contracture in children with brachial plexus birth palsy. J Bone Joint Surg Am 94:403-409, 2012

46. Shigematsu K, Yajima H, Kobata Y, Kawamura K, Maegawa N, Takakura Y: Oberlin partial ulnar nerve transfer for restoration in obstetric brachial plexus palsy of a newborn: case report. J Brachial Plex Peripher Nerve Inj 1:3, 2006

47. Sibinski M, Sherlock DA, Hems TE, Sharma H: Forearm rotational profile in obstetric brachial plexus injury. J Shoulder Elbow Surg 16:784-787, 2007

48. Siqueira MG, Socolovsky M, Heise CO, Martins RS, Di Masi G: Efficacy and safety of Oberlin's procedure in the treatment of brachial plexus birth palsy. Neurosurgery 71:11561161,2012

49. Somashekar DK, Di Pietro MA, Joseph JR, Yang LJ, Parmar HA: Utility of ultrasound in noninvasive preoperative workup of neonatal brachial plexus palsy. Pediatr Radiol 46:695-703, 2016

50. Spires MC, Brown SM, Chang KW, Leonard JA, Yang LJ: Interrater reliability of electrodiagnosis in neonatal brachial plexopathy. Muscle Nerve 55:69-73, 2017

51. Tse R, Kozin SH, Malessy MJ, Clarke HM: International Federation of Societies for Surgery of the Hand Committee report: the role of nerve transfers in the treatment of neonatal brachial plexus palsy. J Hand Surg Am 40:1246-1259, 2015

52. Tse R, Nixon JN, Iyer RS, Kuhlman-Wood KA, Ishak GE: The diagnostic value of CT myelography, MR myelography, and both in neonatal brachial plexus palsy. AJNR Am J Neuroradiol 35:1425-1432, 2014

53. van der Sluijs MJ, van Ouwerkerk WR, van der Sluijs JA, van Royen BJ: Elbow flexion contractures in childhood in obstetric brachial plexus lesions: a longitudinal study of 20 neurosurgically reconstructed infants with 8-year follow-up. J Brachial Plex Peripher Nerve Inj 10:e15-e22, 2015

54. van Ouwerkerk WJ, Uitdehaag BM, Strijers RL, Frans N, Holl K, Fellner FA, et al: Accessory nerve to suprascapular nerve transfer to restore shoulder exorotation in otherwise spontaneously recovered obstetric brachial plexus lesions. Neurosurgery 59:858-869, 2006

55. Waters PM: Comparison of the natural history, the outcome of microsurgical repair, and the outcome of operative reconstruction in brachial plexus birth palsy. J Bone Joint Surg Am 81:649-659, 1999

56. Wilson TJ, Chang KW, Chauhan SP, Yang LJ: Peripartum and neonatal factors associated with the persistence of neonatal brachial plexus palsy at 1 year: a review of 382 cases. $\mathbf{J}$ Neurosurg Pediatr 17:618-624, 2016

57. Yang LJ, Chang KW, Chung KC: A systematic review of nerve transfer and nerve repair for the treatment of adult upper brachial plexus injury. Neurosurgery 71:417-429, 2012

\section{Disclosures}

The authors report no conflict of interest concerning the materials or methods used in this study or the findings specified in this paper. 


\section{Author Contributions}

Conception and design: Yang, Popadich. Acquisition of data:

Yang, Popadich. Analysis and interpretation of data: Chang, Wilson. Drafting the article: Chang. Critically revising the article:

Yang, Chang, Wilson, Brown, Chung. Reviewed submitted version of manuscript: all authors. Approved the final version of the manuscript on behalf of all authors: Yang. Statistical analysis: Chang. Administrative/technical/material support: Yang, Popadich. Study supervision: Yang, Chung.

\section{Supplemental Information}

\section{Online-Only Content}

Supplemental material is available with the online version of the article.

Appendix. https://thejns.org/doi/suppl/10.3171/2017.8.PEDS 17160 .

\section{Current Affiliations}

Dr. Wilson: Department of Neurosurgery, Stanford University, Stanford, CA.

\section{Correspondence}

Lynda J. S. Yang, Department of Neurosurgery, University of Michigan, 1500 E Medical Center Dr., 3552 Taubman Center, Ann Arbor, MI 48109-5338. email: ljsyang@med.umich.edu. 